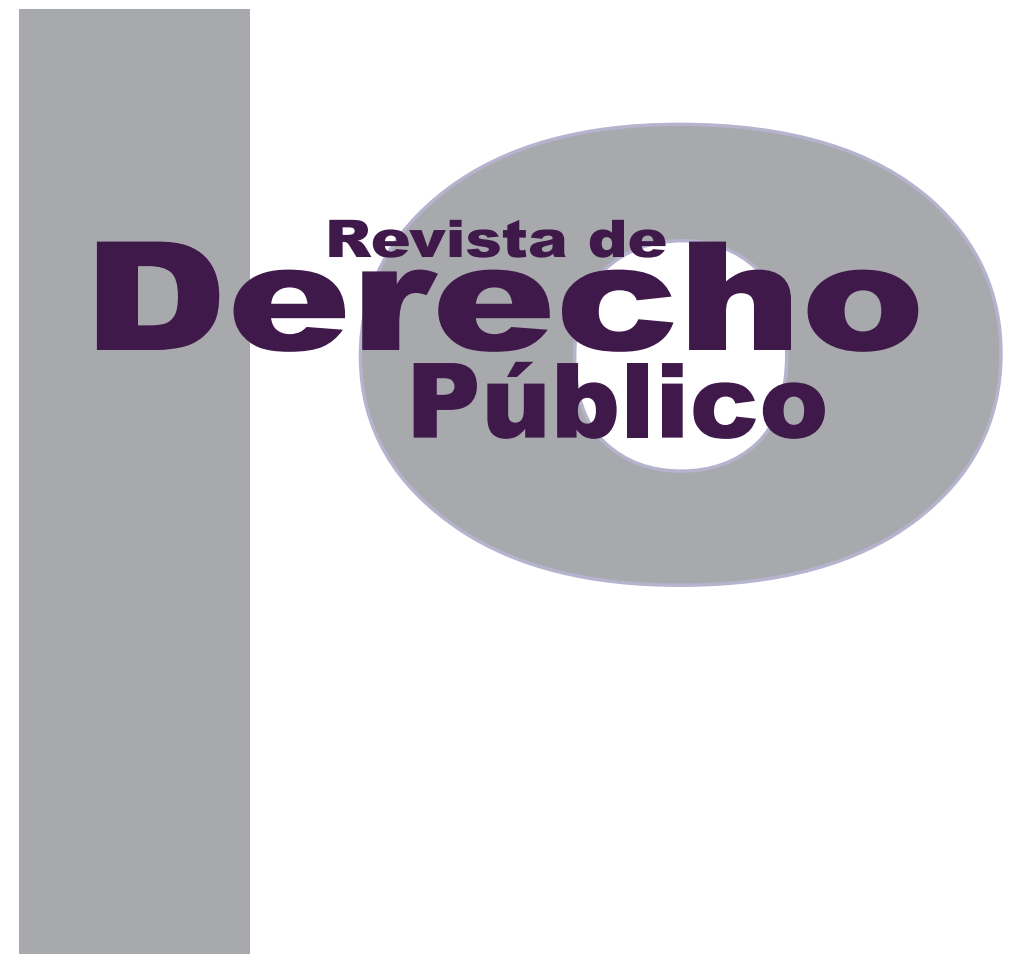

\title{
RECOMENDACIÓN U OBLIGACIÓN: ANÁLISIS DE LAS DECISIONES DEL CONSEJO DE ADMINISTRACIÓN DE LA OIT EN LA JURISPRUDENCIA CONSTITUCIONAL COLOMBIANA
}

\author{
CARlos ANDRÉS Rodríguez SCHRAder
}

Documento de reflexión no derivado de investigación

Universidad de los Andes

Facultad de Derecho

Revista de Derecho Público N. ${ }^{\circ} 32$

Enero - Junio de 2014. ISSN 1909-7778 


\section{Recomendación u obligación: análisis de las decisiones del consejo de administración de la OIT en la jurisprudencia constitucional colombiana}

\section{Resumen}

En el presente trabajo se hace: una revisión de la literatura existente en Colombia sobre la Organización Internacional del Trabajo (оाт); un estudio de su estructura organizacional, sus procedimientos, sus normas y la aplicabilidad y adjudicación de estas últimas en el ordenamiento jurídico colombiano a nivel constitucional; $y$ un recuento sobre sus inicios y su estructura. Se estudian las normas internacionales del trabajo (NIT), su procedimiento, su obligatoriedad y sus mecanismos de cumplimiento. Se analizan las decisiones del Consejo de Administración de la oır, por medio de sus comités, todo esto a la luz de la jurisprudencia constitucional colombiana. El trabajo cierra con una conclusión crítica sobre las decisiones de la Corte Constitucional relacionadas con el tema.

Palabras claves: ILO, OIT, NIT, ILS, Corte Constitucional, normas internacionales del trabajo, Consejo de Administración, convenios, bloque de constitucionalidad.

\section{Recommendation or obligation: Analysis of the decisions of the ILO'S governing body in colombian constitutional case law}

\section{Abstract}

This paper reviews the existing literature in Colombia on the International Labour Organization (ILO), as well as a study of its organizational structure, procedures, rules and their applicability in the Colombian legal system, at the constitutional level. This paper also makes an account of the beginnings and the structure of the ILo. The International Labour Standards (ILS), their procedure, their obligations and their enforcement mechanisms are also examined throughout this paper. Finally, the decisions of the Governing Body of the ıo are analyzed through its different committees, all of them in the light of the Colombian constitutional jurisprudence. The paper closes with a critical conclusion regarding the Colombian Constitutional Court's decisions related to the subject.

Keywords: ILO, OIT, NIT, ILS, Colombian Constitutional Court, International Labour Standards, Governing Body, Conventions, enforcement.

\section{Recomendação ou obrigação: análise das decisões do Conselho de Administração da OIT na jurisprudência constitucional colombiana}

\section{Resumo}

No presente trabalho é feita: uma revisão da literatura existente na Colômbia sobre a Organização Internacional do Trabalho (оाт); um estudo de sua estrutura organizacional, seus procedimentos, suas normas e a aplicabilidade e adjudicação destas últimas no ordenamento jurídico colombiano a nível constitucional; e um recuento sobre seus inícios e sua estrutura. São estudadas as normas internacionais do trabalho (NIT), seu procedimento, sua obrigatoriedade e seus mecanismos de cumprimento. São analisadas as decisões do Conselho de Administração da oıt, por meio de seus comitês, tudo isto à luz da jurisprudência constitucional colombiana. 0 trabalho acaba com uma conclusão crítica sobre as decisões da Corte Constitucional relacionadas com o tema.

Palavras-chaves: ILO, OIT, NIT, ILS, Corte Constitucional, normas internacionais do trabalho, Conselho de Administração, convênios, bloco de constitucionalidade. 


\section{SUMARIO}

Introducción - I. INICIOS, OBJETO Y ESTRUCTURA DE LA OIT - A. Antecedentes históricos y objeto B. Estructura de la OIT - 1. Órgano plenario: la Conferencia Internacional del Trabajo - 2. Órgano ejecutivo: el Consejo de Administración - i. Comisión de Expertos en Aplicación de Convenios y Recomendaciones- ii. Comité de Libertad Sindical - iii. Comités o comisiones ad hoc - iv. Comisión de Encuesta - v. Comisión de Investigación y Conciliación en Materia de Libertad Sindical - 3. Órgano administrativo: la Oficina Internacional del Trabajo - 4. Órgano judicial: la Corte Internacional de Justicia - II. NORMAS INTERNACIONALES DEL TRABAJO: PROCEDIMIENTO DE ADOPCIÓN Y MECANISMOS DE CUMPLIMIENTO - 1. Procedimiento de adopción - 2. Mecanismos de cumplimiento - III. LAS DECISIONES DEL CONSEJO DE ADMINISTRACIÓN - A. Jurisprudencia constitucional - 1. Bloque de constitucionalidad según la Corte Constitucional - 2. Jurisprudencia constitucional sobre las decisiones del Comité de Libertad Sindical - IV. CONCLUSIONES - Bibliografía. 


\title{
Recomendación u obligación: análisis de las decisiones del consejo de administración de la OIT en la jurisprudencia constitucional colombiana $^{1}$
}

\author{
Carlos Andrés Rodríguez Schrader
}

Introducción

Las condiciones, las reglas y los distintos aspectos aplicables a la relación y el lugar de trabajo son cuestiones que han preocupado y generado tensión entre los trabajadores y los empleadores, desde el advenimiento de la revolución industrial (Von Potobsky y Bartolomei, 1990). La misma dureza de las condiciones propias del trabajo durante la citada revolución motivó el desarrollo de ideas de tipo social, que terminaron concretándose primeramente en la demanda de una reglamentación internacional para disminuir las penurias de los trabajadores de la época, que como consecuencia condujeron, al término de la Primera Guerra Mundial, a la creación de la Organización Internacional del Trabajo (оІт) (Von Potobsky y Bartolomei, 1990).

1 Cómo citar este artículo: Rodríguez Schrader, C. A. (Junio, 2014). Recomendación u obligación: análisis de las decisiones del Consejo de Administración de la OIT en la jurisprudencia constitucional colombiana. Revista de Derecho Público, 32.

2 Politólogo y abogado, pregrados en Ciencia Política y Derecho de la Universidad de los Andes
Su importancia fue reconocida en 1969 con el premio Nobel de la Paz (Rodgers, Lee, Swepston y van Daele, 2009) y por la Organización de Naciones Unidas al establecerla como una agencia especializada por medio de la Declaración de Filadelfia de 1944 (Von Potobsky y Bartolomei, 1990). Actualmente cuenta con 183 Estados miembro entre los cuales procura "garantizar que sus normas sean respetadas tanto en sus principios como en la práctica, a los fines de poder dar cumplimiento efectivo a sus más caros anhelos, que son el trabajo decente y productivo para mujeres y hombres en condiciones de libertad, igualdad, seguridad y dignidad humana" (Rodríguez, Belkis y Yanuzzi, 2010).

El presente trabajo hace una revisión de la literatura existente en Colombia sobre esta organización internacional de derecho público, como también un estudio de su estructura organizacional, sus procedimientos, sus normas y la aplicabilidad y adjudicación de estas últimas en el ordenamiento jurídico colombiano a nivel constitucional. La principal razón de este escrito es re- 
saltar la relevancia que tienen las normas internacionales del trabajo (NIT) en el ordenamiento jurídico nacional, puesto que según los artículos 53, 93 y 94 de la Constitución Política de 1991 (CN) los convenios debidamente ratificados prevalecen en el orden interno y su contenido en cuanto a derechos fundamentales es aplicable, así no estén nominados expresamente en el texto de la Constitución, por hacer parte del llamado bloque de constitucionalidad 'en sentido estricto' (sentencias C-574 de 1992, C-225 de 1995, C-191 de 1998 y C-1022 de 1999, entre otras), formando un conjunto normativo de igual rango (sentencia C-067 de 2003).

Las siguientes razones, no jurídicas, demuestran la importancia académica de este texto: el poco desarrollo doctrinal sobre el tema en la literatura colombiana ${ }^{3}$, su insuficiente interpretación por parte de la jurisprudencia nacional ${ }^{4} \mathrm{y}$ la falta de trabajos sobre el efecto que tienen en nuestro orden interno las recomendaciones del Consejo de Administración de la oІт, expresadas a través de sus comités ad hoc y su Comité de Libertad Sindical.

Lo anterior ha podido llevar a que el estudio sobre la olt y los distintos convenios ratificados

3 La gran mayoría de escritos que se encuentran son recopilatorios de convenios de la оіт o discusiones específicas sobre algunos de estos, realizadas por el Colegio de Abogados Especializados en Derecho del Trabajo y Seguridad Social, así como por el Ministerio del Trabajo. Sin embargo, también existe literatura colombiana de este mismo tipo elaborada por autores especializados como Triana (1978) y Monroy Cabra (1977).

4 Aunque este tema será revisado en un capítulo específico más adelante, se pueden citar las siguientes sentencias: T-568 de 1999, T-603 de 2003, T-979 de 2004 y T-171 de 2011 de la Corte Constitucional; y el fallo del 8 de octubre de 1999 de la Sala de Casación Laboral de la Corte Suprema de Justicia. por el Estado hayan quedado reservados a los sindicatos de distintos grados, a las diferentes organizaciones representativas de los empleadores y a fuentes europeas o eurocéntricas (Van Daele, 2010). Falta, entonces, un trabajo de carácter académico que explique, desarrolle e introduzca localmente a esta organización internacional, a sus distintas normas y mecanismos de cumplimiento, sobre todo cuando estos, según la Corte Constitucional, pueden hacerse cumplir en Colombia por medio de la acción de tutela (sentencia T-171 de 2011).

En consecuencia, el problema de investigación que pretende responder el presente trabajo es el siguiente: ¿cuál es el valor y el efecto jurídico que tienen en Colombia las normas internacionales del trabajo y las decisiones del Consejo de Administración de la olt expresadas por medio de sus comités ad hoc y su Comité de Libertad Sindical?

La hipótesis que se defiende es la siguiente: el poco desarrollo y la insuficiente interpretación doctrinal y jurisprudencial ${ }^{5}$ (sobre todo por la Corte Suprema de Justicia) acerca de las deci-

5 Según Segura (2012), la Corte Suprema ha sido enfática en interpretar el alcance de las decisiones de los órganos de la OIT como no vinculantes: "la sentencia con radicación 19701, de la Corte Suprema de Justicia, Sala Laboral, del 28 de marzo de 2003, (...) y la sentencia con radicación 20063, del 6 de agosto de 2003, (...) a pesar de que analizan el efecto vinculante de las recomendaciones proferidas por el Comité de Libertad Sindical, en línea con la sentencia proferida en 1999, indican que no podía un órgano supranacional, sin competencia judicial, imponer al Estado como obligación el que un tercero imparcial conociera de los casos de ilegalidad de la huelga. De otra parte, la sentencia 32703, proferida el 31 de mayo de $2011,(\ldots)$ trascribe los argumentos esbozados por la Corte en la sentencia 19701 y señala que los órganos de control no están facultados para imponer obligaciones a los estados miembros, y que las "invitaciones" o recomendaciones no son reglas vinculantes". Esta interpretación desafortunada, niega y contraría completamente la jurisprudencia de la Corte Constitucional analizada en el presente trabajo. 
siones del Consejo de Administración de la olT, incluida la concepción jurisprudencial vigente y la diferenciación del llamado bloque de constitucionalidad 'en sentido estricto' y 'en sentido lato' (sentencia C-401 de 2005, entre otras), han desembocado en darle mayor alcance y efecto constitucional a las decisiones del Comité de Libertad Sindical.

Lo anterior ha llevado a que en Colombia, para el cumplimiento y ejecución de las decisiones de este órgano que no versen sobre los derechos fundamentales a la negociación colectiva y a la asociación sindical, solamente proceda la acción de tutela, entre otros temas desarrollados en otros convenios. Por esta razón, en el presente trabajo -a diferencia de otros como el de Ostau de Lafont y Niño, 2011; Segura, 2012- se aboga porque el alto tribunal constitucional colombiano cambie su jurisprudencia, para poder amparar también por medio de tutela las decisiones que atiendan otros derechos fundamentales protegidos en los convenios de la olt ratificados por Colombia, y darles un alcance y efecto coherente desde un punto de vista formal y material dentro del ordenamiento jurídico colombiano.

El objetivo, entonces, es contribuir a llenar este vacío en la literatura colombiana y dar un paso adelante en el análisis crítico de la jurisprudencia de la Corte Constitucional (y en parte de la Corte Suprema) sobre el tema. Adicionalmente, hacer un poco más pública la información relativa a la oाт, que hasta el momento ha sido en su mayoría publicada por la misma organización a través de su Oficina Internacional del Trabajo.
El desarrollo del presente texto es el siguiente: primero se hace un recuento sobre los inicios y la estructura de la ort; en segundo lugar se estudian las NIT, su procedimiento, su obligatoriedad (lo cual incluye la pretensión de regulación universal de instrumentos no vinculantes en sentido formal por medio de las llamadas recomendaciones) y sus mecanismos de cumplimiento; en tercer lugar se analizan las decisiones del Consejo de Administración de la oIT, concretamente de sus comités ad hoc y del Comité de Libertad Sindical a la luz de la jurisprudencia constitucional colombiana, para cerrar finalmente con una conclusión crítica de lo analizado durante todo el trabajo.

\section{INICIOS, OBJETO Y ESTRUCTURA DE LA OIT}

Actualmente, la oाт es un organismo intergubernamental de derecho internacional público, que opera como agencia especializada del Consejo Económico y Social (Ecosoc) de Naciones Unidas. Cuenta con 183 Estados miembro y una estructura "tripartita" (Rodríguez, 2010; Tsogas, 2001), que reúne a los representantes de gobiernos, empleadores y trabajadores (Bronstein, 2009; оाт, 2005; Tsogas, 2001). Dentro del seno de la oIt se encuentra la Conferencia Internacional del Trabajo, que se reúne una vez al año y su función legislativa consiste en adoptar las normas internacionales del trabajo, es decir, los convenios y recomendaciones. Los primeros tienen carácter vinculante para el Estado miembro que los ratifique; las segundas no requieren ratificación pero las directrices que ofrecen pue- 
den llegar a orientar la política y las acciones nacionales (Constitución oIт, art. 19, numerales $5 b$ y $6 b)$. Colombia es miembro fundador de la оाт, participa en la Conferencia Internacional del Trabajo anualmente y ha ratificado varios convenios durante sus años de membresía. ${ }^{6}$

Las características anteriormente descritas, la estructura y funcionamiento de la oIT han cambiado desde su nacimiento a finales de la Primera Guerra Mundial (fines del siglo XX y antes de la Organización de las Naciones Unidas), evolución que es necesario conocer para poder comprender en su totalidad el problema de investigación que pretende responder el presente trabajo.

\section{A. Antecedentes históricos y objeto}

La extrema "dureza de las condiciones de trabajo durante la revolución industrial motivaron el desarrollo de ciertas ideas sociales que se concretaron primeramente en la demanda de una reglamentación internacional para paliar las penurias de los obreros, y condujeron al término de la Primera Guerra Mundial a la creación de la oIT" (Von Potobsky y Bartolomei, 1990). Estas ideas sociales tuvieron una inspiración humanitaria pero "la internacionalización de toda acción protectora surgió rápidamente, debido al temor de los industriales y gobiernos de quedar rezagados en la competencia comercial al to-

6 Los convenios (en vigor) ratificados por Colombia hasta la fecha del presente escrito son los siguientes: $29,87,98,100,105,111,138,182$, $81,129,144,1,2,3,6,8,9,11,12,13,14,16,17,18,19,22,23,24$, $25,26,30,52,80,88,95,99,101,106,116,136,151,154,159,160$, 161, 162, 167, 169 y 170 (Ministerio de Trabajo y Seguridad Social, 2000). mar medidas tuitivas unilaterales que aumentaran los costos de producción frente a los demás países" (Von Potobsky y Bartolomei, 1990). En otras palabras, los Estados de la época tenían necesidad de tomar medidas en conjunto, para que dentro de la competencia comercial no se generaran distorsiones por las potenciales medidas unilaterales adoptadas por los Estados en referencia a sus condiciones laborales a nivel local. De esta manera, y como consecuencia, se propuso una reglamentación social internacional que sería adoptada simultáneamente por los diversos Estados, lo cual culminó con la creación de la oіт (Rodgers, Lee, Swepston y Van Daele, 2009; Von Potobsky y Bartolomei, 1990).

Cronológicamente, existen diferencias entre quienes opinan que la idea original de fundar una organización de carácter internacional surgió de los trabajadores (Monroy, 1977) o de los industriales (Von Potobsky y Bartolomei, 1990). Sin embargo, teniendo en cuenta que el derecho internacional es creado por y para los Estados como sujetos fundamentales de este (Aust, 2005), es necesario establecer que las propuestas iniciales de una legislación internacional laboral fueron expuestas primeramente por el inglés Charles Hindley, el belga Edouard Ducpétiaux, los franceses J. A. Blanqui, Louis René Villarmé y Daniel Le Grand, quienes a partir de 1844 formularon una serie de llamamientos y de proyectos concretos dirigidos a distintos gobiernos, tendientes a "proteger la clase obrera contra el trabajo precoz y excesivo, a fin de impedir su explotación y la competencia comercial entre los países, basada en la imposición de condiciones de trabajo diferentes en cada uno de ellos" 
(Von Potobsky y Bartolomei, 1990). Finalmente, gracias a los esfuerzos conjuntos de distintas fuentes, Alemania convocó a la primera conferencia intergubernamental en Berlín, en 1890, para explorar de forma oficial la posibilidad de adoptar y aplicar una legislación internacional del trabajo (Von Potobsky y Bartolomei, 1990).

Las intenciones de crear un cuerpo normativo internacional laboral anteceden al siglo XX, lo cual muestra que dicha necesidad ya estaba presente en los distintos Estados. Sin embargo, fue solo hasta el año 1900, en el marco del Segundo Congreso Internacional del Trabajo, realizado en París, que se adoptaron los estatutos de la llamada Asociación Internacional para la Protección Legal de los Trabajadores, la cual creó asimismo la Oficina Internacional del Trabajo como secretaría permanente de aquella, con sede en Basilea (Von Potobsky y Bartolomei, 1990). Siguiendo una propuesta de la mencionada asociación se concluyeron los dos primeros convenios internacionales del trabajo, que tratan sobre la prohibición del fósforo blanco y del trabajo nocturno de las mujeres en la industria, los cuales fueron ratificados por la mayor parte de los países signatarios (Von Potobsky y Bartolomei, 1990). En 1910, “la Asociación promovió la reunión de una nueva Conferencia con el objeto de adoptar dos convenios más sobre la prohibición del trabajo nocturno de los jóvenes en la industria y la jornada máxima de diez horas para mujeres y niños" (Von Potobsky y BartoIomei, 1990). Una primera reunión técnica tuvo lugar en 1913, pero la reunión diplomática no pudo celebrarse debido al estallido de la Primera Guerra Mundial.
Al finalizar la guerra, y en desarrollo de las negociaciones del Tratado de Paz de Versalles (Bronstein, 2009; Rodgers, Lee, Swepston y Van Daele, 2009), se constituyó la Comisión de Legislación Internacional del Trabajo, la cual estuvo compuesta por representantes de los gobiernos, sindicalistas y universitarios. Esta Comisión estuvo presidida por el reconocido sindicalista Samuel Gompers, de la American Federation of Labor (AFL) y presentó un "proyecto de acuerdo" sobre la creación de la oІт (McKillen, 2010), cuyo objeto principal era la "elaboración de un sistema normativo internacional, y que incluía las llamadas "cláusulas obreras" con el carácter de principios fundamentales de toda legislación laboral internacional"7 (Von Potobsky y Bartolomei, 1990). Este proyecto, adoptado finalmente por la Conferencia de la Paz, es decir, por los países vencedores, quedó insertado como Parte XIII del Tratado de Versalles (Tsogas, 2001), el cual fue concluido en 1919 (ort, 2009; Von Potobsky y Bartolomei, 1990).

La Organización tiene personalidad jurídica propia, aunque luego de la Declaración de Filadelfia fue vinculada al Sistema de Naciones Unidas mediante acuerdo celebrado con el Ecosoc, el 30 de mayo de 1946, que dejó como competencia de la olt el vasto campo de las actividades laborales y de los derechos humanos y sociales

7 Estos principios fundamentales, de manera resumida, eran los siguientes: (i) el trabajo no debe considerarse simplemente como una mercancía, (ii) la existencia del derecho de asociación de empleadores y trabajadores, (iii) el pago de un salario que asegure un nivel de vida conveniente, (iv) la jornada de ocho horas o cuarenta y ocho horas semanales, (v) el descanso semanal, (vi) la supresión del trabajo de los niños y la reglamentación del trabajo de los menores, (vii) salario igual por trabajo de igual valor, (viii) trato económico equitativo para los trabajadores extranjeros y (ix) organización de un servicio de inspección (Von Potobsky y Bartolomei, 1990). 
relacionados con estas (Tsogas, 2001; Rodríguez, 2010; Von Potobsky y Bartolomei, 1990).

\section{B. Estructura de la OIT}

De acuerdo con la literatura especializada en el derecho de los organismos internacionales, las organizaciones intergubernamentales suelen tener como mínimo tres órganos: un órgano plenario, un órgano ejecutivo y un órgano administrativo (Klabbers, 2002). Sin embargo, dentro del estado del arte se encuentran académicos que incluyen un cuarto órgano, aunque aceptan que es menos frecuente: el judicial (Ureña, 2008). La presente sección se enfoca en la estructura de las organizaciones internacionales, sus órganos y cómo en ella encaja la configuración de la oıт. Antes de hacer esta breve reseña es importante establecer que la Constitución de la от, como tratado constitutivo de una organización internacional (Ureña, 2008), en su artículo 2 establece como órganos principales:

a) la Conferencia General de los representantes de los Miembros;

b) el Consejo de Administración (...); y

c) la Oficina Internacional del Trabajo.

La Conferencia General es más conocida como Conferencia Internacional del Trabajo.

Gráfico 1. Estructura de la OIT

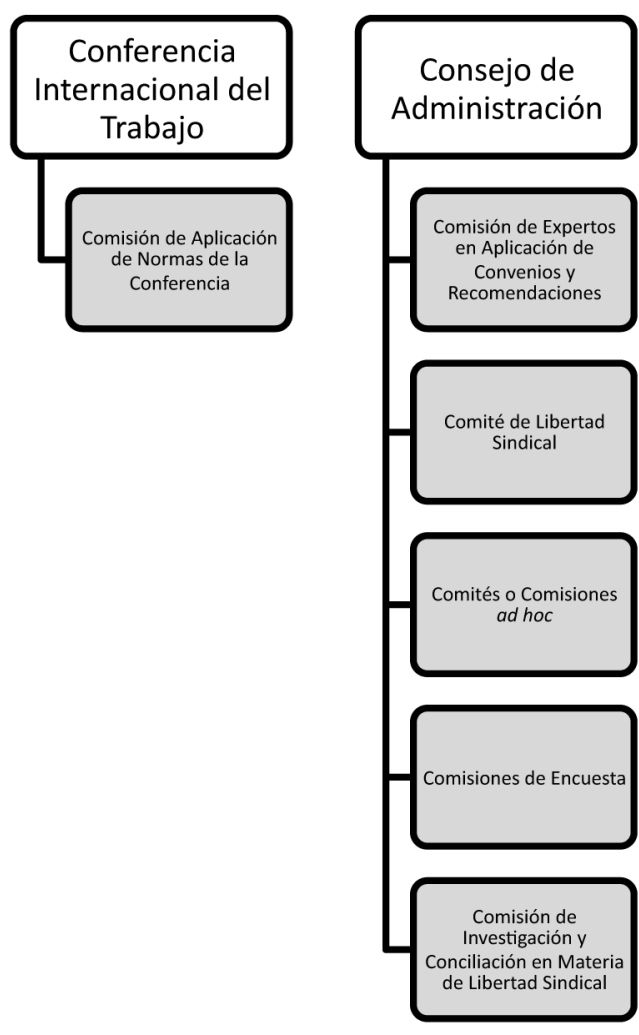




\section{1. Órgano plenario: la Conferencia Internacional del Trabajo}

El órgano plenario es aquel en el "que se ven representados todos los Estados miembro. Usualmente, en él se toman las decisiones de carácter normativo y las decisiones que afectarán de manera importante las relaciones de la organización con terceros" (Ureña, 2008). Toda organización internacional tiene, por lo general, un órgano plenario. Se reúne en intervalos regulares, esto es, una vez al año, o una vez cada dos, tres o cinco años (Klabbers, 2002). El órgano plenario es, entonces, "la más alta instancia en la voluntad de los Estados miembro, reflejada por sus respectivos diplomáticos" (Ureña, 2008). Las personas que componen el plenario son representantes de sus gobiernos, pero esta regla general no siempre se aplica. Una muy buena excepción a dicha regla es la oıt, en cuyo órgano plenario -la Conferencia Internacional del Trabajo-, cada Estado miembro tiene dos delegados del gobierno, uno de los trabajadores y uno de los empleadores (Constitución de la ort, art. 3), los cuales se reúnen normalmente en junio de cada año (Klabbers, 2002). "La Conferencia Internacional del Trabajo es el órgano supremo" (Von Potobsky y Bartolomei, 1990).

Dentro del órgano plenario se toman decisiones que terminan siendo estándares de conducta y de funcionamiento para los Estados miembro respecto del objeto mismo de la organización internacional, materializados en tratados de derecho internacional (Klabbers, 2002). Según Von Potobsky y Bartolomei (1990), su función básica es la discusión y adopción de instrumentos in- ternacionales de carácter normativo; en el caso de la ort, los artículos 19 y 20 de su Constitución establecen que estas decisiones se reducen a las normas internacionales del trabajo, las cuales están compuestas por convenios y recomendaciones, como se explica detenidamente más adelante.

Ahora, hay que dejar claro que los órganos plenarios también pueden cumplir otras funciones distintas a la adopción de tratados internacionales, por ejemplo, contener un órgano que tenga como función el control y examen del cumplimiento por parte de los Estados miembro de las obligaciones emanadas de las decisiones tomadas dentro del plenario. Este es el caso de la Comisión de Aplicación de Normas de la Conferencia de la oıt, de composición tripartita -gobiernos, empleadores y trabajadores- cuyos representantes son escogidos por estos mismos. Su principal función es examinar las medidas adoptadas por los Estados miembro a la luz de las disposiciones de los convenios en que son parte, y presentar un informe a la Conferencia del Trabajo (отт, 2006).

\section{2. Órgano ejecutivo: el Consejo de Administración}

Los organismos internacionales también cuentan usualmente con un órgano ejecutivo "que se encarga de hacer cumplir los actos emitidos por la propia organización. La característica especial de tal órgano es su capacidad de tomar decisiones vinculantes, aún acción armada" (Ureña, 2008), como es el caso del Consejo de Seguridad de las Naciones Unidas. Sin embar- 
go, existen otros órganos ejecutivos cuyas actividades se reducen a cuestiones preparatorias y actividades puramente operativas, como por ejemplo la Comisión de la Comunidad Europea (Klabbers, 2002). El Consejo de Administración de la oıt encuadra más en el segundo grupo; sin embargo, como veremos más adelante, en Colombia la jurisprudencia de las altas Cortes le han dado mayor importancia a sus decisiones creando una especie de híbrido, lo cual constituye el objeto de análisis principal del presente trabajo.

Las funciones del Consejo de Administración de la oIT, dispersas tanto en su Constitución como en su reglamento, son las siguientes: (i) fijar el orden del día de la Conferencia, (ii) designar al Director General de la Oficina Internacional de Trabajo y dar a este las instrucciones necesarias para ejecutar su trabajo, (iii) elaborar el programa y presupuesto de la organización, (iv) fijar el orden del día de las distintas reuniones que convoca, (v) determinar la política de cooperación técnica, (vi) vigilar la ejecución de los programas respectivos y (vii) constituir e integrar las comisiones y comités que considere necesarios (Von Potobsky y Bartolomei, 1990). Esta última actividad, en orden a un trabajo más ordenado y más estructurado, y a facilitar la división funcional de sus actividades. En el caso del Consejo de Administración de la olt, este ha constituido los llamados órganos regulares de control, a saber: (i) la Comisión de Expertos en Aplicación de Convenios y Recomendaciones, (ii) el Comité de Libertad Sindical, (iii) comités o comisiones ad hoc, (iv) comisiones de Encuesta y (v) la Comisión de Investigación y Conciliación en Materia de Libertad Sindical (oIt, 2006). A continuación se hace una breve reseña de cada una de ellas.

\section{i. Comisión de Expertos en Aplicación de Convenios y Recomendaciones}

Según el Manual sobre procedimientos en materia de convenios y recomendaciones internacionales del trabajo (оІт, 2006):

los miembros de la Comisión son nombrados por el Consejo de Administración, a propuesta del Director General y por un periodo de tres años. Se les escoge, a título personal, de entre personalidades independientes, totalmente imparciales y habida de su competencia técnica. (...) Los principios fundamentales exigen que la Comisión dé muestras de independencia, imparcialidad y objetividad al indicar en qué medida le parece que la situación existente en cada Estado concuerda con los términos de los convenios y con las obligaciones aceptadas de conformidad con la Constitución de la oıт.

En términos generales, según los artículos 19, 22 y 35 de la Constitución de la olt, la función de este órgano es la de examinar las informaciones y memorias periódicas y excepcionales comunicadas por los Estados miembro, documentos que establecen las medidas de iure y de facto adoptadas a nivel local en cumplimiento de los convenios ratificados por estos (Von Potobsky y Bartolomei, 1990). Al final, la Comisión redacta un reporte en el cual consta toda la información examinada y destaca los puntos de interés general o los problemas especiales que deben tomar en consideración el Consejo de Administración, la Conferencia del Trabajo o los Estados 
miembro para el cumplimiento efectivo de las normas internacionales del trabajo (Von Potobsky y Bartolomei, 1990). Cabe recordar que el informe de la Comisión se somete, en primer lugar, al Consejo de Administración y posteriormente a la Conferencia del Trabajo que se reúne normalmente en junio de cada año (oıt, 2006).

\section{ii. Comité de Libertad Sindical}

Es "un órgano tripartito del Consejo de Administración, y está compuesto de nueve de sus miembros y nueve suplentes, que actúan a título personal, más un presidente independiente. Celebra sus reuniones a puerta cerrada (tres veces al año), sus documentos de trabajo son confidenciales y sus decisiones se toman en la práctica por consenso" (oIT, 2006). Examina y decide sobre las quejas y reclamaciones -también llamados procedimientos especiales- entabladas en contra de un Estado miembro, independiente de que este haya o no ratificado alguno de los convenios relacionados con la libertad sindical $^{8}$ (Von Potobsky y Bartolomei, 1990), ya que en virtud a la Constitución de la ort todos los Estados miembro tienen la obligación de reconocer este principio (оІт, 2006) y derecho fundamental (sentencia T-171 de 2011). Sus decisiones son conocidas como recomendaciones, y son parte del objeto principal de análisis del presente trabajo.

8 Los principales convenios que abordan el derecho a la libertad sindical y la negociación sindical son los convenios 87 y 98 de 1948 y 1949 respectivamente.

\section{iii. Comités o comisiones ad hoc}

El Consejo de Administración también hace uso de la facultad de crear comités o comisiones ad hoc en caso de iniciar un procedimiento especial (queja o reclamación) respecto de cualquier otro convenio distinto a aquellos sobre libertad sindical, los cuales, hay que recalcar, son mayoría y no menos importantes desde el punto de vista formal y material. ${ }^{9}$ Si la queja o reclamación es admitida, el Consejo de Administración constituye una comisión o comité para que la examine, y formule sus conclusiones y recomendaciones a las partes interesadas (oIt, 2006). Estas recomendaciones, según la opinión de nuestras altas Cortes, tienen menor importancia que aquellas del Comité de Libertad Sindical, como se verá en el aparte correspondiente.

\section{iv. Comisión de Encuesta}

La Comisión de Encuesta se constituye una vez se determina la importancia y urgencia de atender la queja contra un Estado miembro, por incumplimiento de un convenio ratificado por otro Estado miembro. Su misión es desplazarse al territorio del Estado miembro contra el cual se ha iniciado el procedimiento y efectuar las correspondientes investigaciones, para luego establecer sus propias conclusiones y presentar el informe correspondiente al Consejo de Administración. A pesar de su importancia no existe un reglamento en relación con el procedimiento

\footnotetext{
9 Dentro de los convenios fundamentales — de obligatorio cumplimiento hayan sido ratificados o no-y prioritarios —impulsados por el Consejo de Administración para ser ratificados por los Estados miembro- se encuentran los convenios 29, 81, 100, 105, 111, 122, 129, 144 y 182.
} 
que deben seguir; siempre el Consejo de Administración ha dejado que sea la propia Comisión la que lo determine, en consonancia con su propia Constitución (oIt, 2006). Hay que recalcar que la Comisión de Encuesta es la última instancia que tiene el Consejo de Administración para revisar el cumplimiento de iure y de facto de los Estados miembro, en tanto que para estos el traslado de la Comisión a su territorio es mal visto por la comunidad internacional y puede repercutir negativamente en su imagen (oıт, Centro Internacional de Formación, 2009). Los efectos se pueden calcular teniendo en cuenta que en la actividad interestatal la imagen internacional es un componente fundamental (Aust, 2005).

\section{v. Comisión de Investigación y Conciliación en Materia de Libertad Sindical}

Esta cumple la misma función investigativa que la Comisión de Encuesta pero en cuanto a procedimientos especiales iniciados en contra de un Estado miembro, por el incumplimiento de facto y de iure de convenios relacionados con la libertad sindical (ort, 2006). Vale la pena advertir que al igual que sucede con la Comisión de Encuesta, su traslado al territorio de un Estado es mal visto a nivel internacional (оाт, Centro Internacional de Formación, 2009).

\section{3. Órgano administrativo: la Oficina Internacional del Trabajo}

Las organizaciones internacionales normalmente cuentan con un órgano administrativo, a ve- ces Ilamado Secretariado, "que se encarga de los asuntos que resultan del cumplimiento de la función sustancial de la respectiva organización" (Ureña, 2008). Este usualmente se responsabiliza de los asuntos laborales y del manejo de los recursos físicos, esto es, bienes muebles, inmuebles, contratos, etc. (Ureña, 2008). La Oficina Internacional del Trabajo, sucesora de la antigua Oficina de Basilea, es el secretariado permanente de la oıт (Von Potobsky y Bartolomei, 1990). Sus funcionarios provienen de más de cien países, de los cuales no pueden recibir órdenes por tener la oIT un estatuto internacional propio (Von Potobsky y Bartolomei, 1990). Tiene como función la centralización y distribución de la información sobre la reglamentación del trabajo, estudios, investigaciones, trabajos y consultas, así como preparar la documentación para la Conferencia, el Consejo y las demás reuniones necesarias (Von Potobsky y Bartolomei, 1990).

\section{4. Órgano judicial: la Corte Internacional de Justicia}

Según la literatura sobre derecho de las organizaciones internacionales, "menos comunes que los anteriores tres tipos de órganos son los órganos judiciales" (Ureña, 2008). Así mismo, pueden existir tres modelos de órgano judicial en una organización internacional: (i) el Tribunal de Derechos Humanos, (ii) la Corte Internacional y (iii) el Tribunal Supranacional (Ureña, 2008). De acuerdo con los artículos 29, 30 y 31 de la Constitución de la ort, la Corte Internacional de Justicia es la competente para resolver las dis- 
crepancias de los Estados miembro respecto de los informes de los comités o comisiones del Consejo de Administración rendidos luego de investigar una queja. Esto se debe a la incorporación de la oit al Sistema de las Naciones Unidas en calidad de agencia especializada del Ecosoc. Según el artículo 31 de la misma Constitución "la decisión de la Corte Internacional de Justicia sobre cualquier reclamación o cuestión que se le haya sometido en virtud del artículo 29 será inapelable".

\section{NORMAS INTERNACIONALES DEL TRABAJO: OBLIGATORIEDAD, PROCEDIMIENTO DE ADOPCIÓN Y MECANISMOS DE CUMPLIMIENTO}

Los dos tipos de instrumentos internacionales adoptados en el seno de la olt, concretamente en la Conferencia Internacional del Trabajo, son los convenios y las recomendaciones; a través de estos se expresan las NIT. De acuerdo con Von Potobsky y Bartolomei (2009) “La diferencia básica entre ambos radica en que el convenio está abierto a la ratificación de un Estado miembro, acto que crea para este obligaciones jurídicas internacionales relativas a su aplicación y cumplimiento", en tanto que la recomendación no puede ser ratificada y constituye "solo una guía para una acción nacional en la materia cubierta por este instrumento".

En otras palabras, los convenios son tratados internacionales legalmente vinculantes que pueden ser ratificados por los Estados miembro, mientras que las recomendaciones actúan como directrices no vinculantes. "En muchos casos, un convenio establece los principios básicos que deben aplicar los países que lo ratifican, mientras que una recomendación relacionada complementa al convenio, proporcionando directrices más detalladas sobre su aplicación" (oIt, 2005). Sin embargo, las recomendaciones también pueden ser autónomas, esto es, sin ninguna relación con ningún convenio. Lo anterior evidencia la posibilidad de una regulación universal en el seno de la oІт, a partir de instrumentos no vinculantes en sentido formal como las recomendaciones, pero reconociendo su efecto en el comportamiento de los Estados miembro al impulsarlos a cumplir y a ejecutar los contenidos en ellas desarrollados sin necesidad de una ratificación.

La oit también clasifica dentro de las NIT aquellos convenios que a pesar de no haber sido ratificados por el Estado miembro son vinculantes y, por ende, deben ser acatados por este. A estos el Consejo de Administración los ha llamado convenios fundamentales, los cuales "abarcan temas que son considerados como principios y derechos fundamentales en el trabajo: la libertad de asociación y la libertad sindical, y el reconocimiento efectivo del derecho de negociación colectiva; la eliminación de todas las formas de trabajo forzoso u obligatorio; la abolición efectiva del trabajo infantil; y la eliminación de la discriminación en materia de empleo y ocupación" (оіт, 2005). Específicamente a esta categoría corresponden los convenios $87,98,29,105,138$, 182, 100 y 111. 
Por otro lado, el Consejo de Administración también "ha designado otros cuatro convenios como instrumentos "prioritarios", por lo cual impulsa a los Estados miembro a su ratificación, en razón de su importancia para el funcionamiento del sistema de normas internacionales del trabajo" (оıт, 2005). Estos abarcan temas como la inspección del trabajo, la consulta tripartita y la política de empleo (convenios 81, 129, 144 y 122 respectivamente). La discusión sobre la importancia y el alcance que les ha dado la jurisprudencia colombiana dentro del ordenamiento jurídico nacional será estudiada y analizada más adelante (supra III).

\section{Procedimiento de adopción}

A diferencia de otras organizaciones internacionales, la elaboración y procedimiento de adopción de las NIT en la oIt es un proceso legislativo único que incluye a representantes de los trabajadores, de los empleadores y de los gobiernos. Recientemente, en la publicación Las reglas del juego: una breve introducción a las normas internacionales del trabajo, se resumió de manera precisa y concisa:

En primer lugar, el Consejo de Administración acuerda poner un tema en el orden del día de una futura Conferencia Internacional del Trabajo. La Oficina Internacional del Trabajo prepara un informe que analiza la legislación y la práctica de los Estados miembro respecto del asunto de que se trata. Este informe se envía a los Estados miembro y a las organizaciones de empleadores y de trabajadores para que formulen comentarios al respecto, y se discute en la Conferencia Internacional del Trabajo. Posteriormente, la Oficina prepara un segundo informe que contiene un proyecto de instrumento sobre el que también pueden formularse comentarios. Dicho proyecto se somete a discusión en la siguiente Conferencia, si se considera necesario se enmienda, y se propone para su adopción. Esta "doble discusión" brinda a los participantes en la Conferencia un tiempo suficiente para analizar el proyecto de instrumento y formular comentarios sobre el mismo. Para la adopción de una norma se requiere una mayoría de dos tercios de votos (oIT, 2005).

De lo anterior se desprenden dos cuestiones que vale la pena recalcar. Primera, el proceso de adopción de las NIT en el seno de la oIT es totalmente único entre las organizaciones de derecho internacional, al darle asiento, voz y voto a representantes distintos a los de los gobiernos en la adopción de instrumentos internacionales vinculantes para los Estados miembro, y en la discusión de temas trascendentales para la Organización. Esta característica sui generis hace de la oıт un organismo internacional único en la esfera global, cumpliendo así con los objetivos y funciones trazados por sus fundadores en el sentido de que la opinión y la decisión de los trabajadores y empleadores son cruciales, como ya fue analizado.

Segunda, este proceso de creación de instrumentos de la oıt también es único dentro del Sistema de las Naciones Unidas, al establecer que la adopción de tratados se hará por una mayoría de dos tercios de votos y no por el mecanismo de consenso (Aust, 2005). 
A continuación se explican brevemente los procedimientos especiales que tiene la oाt para ejercer control sobre el cumplimiento por parte de los Estados miembro.

\section{Mecanismos de cumplimiento}

La Constitución de la oाт establece en sus artículos 24 y 26 dos mecanismos de control especiales (procedimientos especiales) para la inspección del cumplimiento de las obligaciones por parte de los Estados miembro. El artículo 24 contiene lo referente al mecanismo de reclamación, el cual consiste en una denuncia interpuesta por "una organización profesional de empleadores o de trabajadores en la que se alegue que cualquiera de los Miembros no ha adoptado medidas para el cumplimiento satisfactorio, dentro de su jurisdicción, de un Convenio en el que dicho Miembro sea parte" [subrayas fuera del texto]. Este tiene como finalidad corroborar que un país Miembro haya cumplido con la obligación de adoptar medidas legislativas (de iure) tendientes a la incorporación del Convenio dentro de su jurisdicción (art. 19, numeral 5b). En este sentido, este es un mecanismo que revisa situaciones no propiamente de hecho, sino se trata de un control de adecuación normativa dentro de las jurisdicciones de Ios Estados miembro, a diferencia de la queja, como se verá a continuación.

El artículo 26 (numerales 1 a 5) se ocupa de lo referente al mecanismo de queja, consistente en la denuncia por un Miembro, o por un delegado de la Conferencia Internacional del Trabajo, respecto de situaciones de hecho (de facto) que demuestren el incumplimiento de las obligaciones tendientes a la aplicación de un convenio ratificado por un país miembro. El Consejo de Administración, que es el que recibe la queja interpuesta, puede iniciar de oficio el procedimiento, si lo considera pertinente (art. 26, numeral 4).

Tanto la reclamación como la queja son interpuestas ante la Oficina Internacional del Trabajo, y como regla general son resueltas por el Consejo de Administración mediante un Comité o Comisión ad hoc (arts. 24 y 26). Adicionalmente, al ser la oIt una agencia especializada del Ecosoc, las quejas también pueden presentarse ante las Naciones Unidas para que esta las remita a la olт. ${ }^{10}$

Sin embargo, como procedimiento especial de control, se encuentra que de conformidad con lo dispuesto en el artículo 26 de la Constitución de la oıт y el reglamento correspondiente, incumbe al Comité de Libertad Sindical (del Consejo de Administración) examinar las quejas que se reciben sobre situaciones de hecho que surjan en los Estados, relacionadas con la violación a la libertad sindical. Este Comité tiene como función y finalidad estudiar la legislación y buscar, junto con el gobierno interesado, las posibilidades de solución a las dificultades frente a casos concretos por vía de acuerdo (sentencia Corte Constitucional T-171 de 2011).

\footnotetext{
10 El reglamento del Comité de Libertad Sindical se encuentra integrado al documento Cuestiones de procedimiento, el cual fue elaborado con informes del Comité desde 1952 hasta 2002. Disponible en: <http:// www.ilo.org/dyn/normlex/es/f?p=NORMLEXPUB:62:40855132647962 24::NO:62:P62_LIST_ENTRIE_ID:2565060:NO\#E1>.
} 
Finalmente, en relación con la queja hay que dejar claro un asunto que puede llegar a ser fuente de discusión. Algunos tratados de derechos humanos de nivel internacional establecen que para que una persona pueda acceder a sus mecanismos de protección y de control tiene que haber agotado previamente los recursos judiciales a nivel interno. ${ }^{11}$ Sin embargo, en ello también la oIt es especial, puesto que de acuerdo con el párrafo 30 del Reglamento del Comité de Libertad Sindical sus mecanismos de control no requieren el cumplimiento de un trámite judicial previo ante las autoridades nacionales.

\section{LAS DECISIONES DEL CONSEJO DE ADMINISTRACIÓN}

Las decisiones del Consejo de Administración en Colombia han sido objeto de pronunciamientos jurisprudenciales y muy poca doctrina. Esto, como se anotó en la parte introductoria, probablemente se deba al poco desarrollo del tema y al acceso limitado a lo producido. Esta sección intenta hacer un barrido de lo dicho por la jurisprudencia constitucional sobre (i) la inclusión de las NIT en el bloque de constitucionalidad 'en sentido estricto' y 'en sentido lato', y (ii) el alcance que tienen en el ordenamiento jurídico colombiano las decisiones del Consejo de Admi-

11 Un ejemplo claro es el agotamiento previo de los recursos internos en el Sistema Interamericano de Protección de los Derechos Humanos. La Convención Americana de Derechos Humanos, artículo 46, numeral 1, literal a) establece: "Para que una petición o comunicación presentada conforme a los artículos 44 ó 45 sea admitida por la Comisión, se requerirá: (...) que se hayan interpuesto y agotado los recursos de jurisdicción interna, conforme a los principios del Derecho Internacional generalmente reconocidos". nistración y sus órganos, haciendo un análisis crítico sobre lo dicho hasta el momento.

Antes de analizar la jurisprudencia de la Corte Constitucional sobre el tema hay que aclarar que la jurisprudencia de la Corte Suprema de Justicia es contraria a esta. Según la Corte Suprema, a pesar de analizar el efecto vinculante de las recomendaciones proferidas por el Comité de Libertad Sindical en algunas decisiones, indica de manera general que: (i) no puede un órgano supranacional, sin competencia judicial, imponer al Estado colombiano como obligación el que un tercero imparcial conozca de los casos de ilegalidad en las la huelgas, ${ }^{12}$ (ii) los órganos de control de la oit no están facultados para imponer obligaciones a los Estados miembros, ${ }^{13}$ (iii) las "invitaciones" o recomendaciones no son reglas vinculantes ${ }^{14} \mathrm{y}$ (iv) las recomendaciones de los órganos únicamente tienen carácter orientativo, interpretativo o aclarativo ${ }^{15}$ (Segura, 2012). La Corte Constitucional, como se verá, sí les da carácter de obligatorias a las decisiones del Comité de Libertad Sindical, hasta el punto de poder ejecutarlas en territorio colombiano en caso de incumplimiento, por medio de la acción de tutela (ver, entre otras, la sentencia C-171 de 2011).

12 Corte Suprema de Justicia. Sala de Casación Laboral. Rad. 1701 del 28 de marzo de 2003. M. P.: Isaura Vargas Díaz.

13 Corte Suprema de Justicia. Sala de Casación Laboral. Rad. 20063 del 6 de agosto de 2003. M. P.: Fernando Vásquez Botero.

14 Corte Suprema de Justicia. Sala de Casación Laboral. Rad. 32703 del 31 de mayo de 2011. M. P.: Jorge Mauricio Burgos.

15 Corte Suprema de Justicia. Sala de Casación Laboral. Rad. 11731 del 8 de octubre de 1999. M. P.: Carlos Isaac Nader. 
Dado que la jurisprudencia constitucional colombiana le ha dado un alcance (limitado como se verá) a las decisiones del Consejo de Administración, el presente trabajo se enfoca en analizarla brevemente para darle más luz al tema y más claridad a la obligatoriedad de las decisiones del órgano ejecutivo de la orт en el contexto legislativo del país.

\section{A. Jurisprudencia constitucional}

La Corte Constitucional le ha dado un amplio desarrollo jurisprudencial a los convenios y las decisiones de los órganos de control de la oıт en el ordenamiento jurídico colombiano, y más específicamente a dos temas: (i) el alcance de las normas internacionales del trabajo por medio del Ilamado bloque de constitucionalidad "en sentido estricto' y 'en sentido lato', y (ii) el alcance de las decisiones del Comité de Libertad Sindical.

En principio, ambos temas parecen no tener mucha conexión, sin embargo, como se verá, están totalmente relacionados en tanto la interpretación que se le ha dado a las normas internacionales del trabajo dentro del bloque de constitucionalidad, sobre todo la sentencia C-401 de $2005,{ }^{16}$ por las repercusiones que ha tenido en el alcance e interpretación de las decisiones del

16 En esta sentencia la Corte hace un recuento de la figura del bloque de constitucionalidad, sobre todo respecto del alcance que tienen los convenios de la oIT en el ordenamiento jurídico colombiano. En esta ocasión estudiaba la constitucionalidad de la expresión "los convenios", contenida en el artículo 19 del Código Sustantivo del Trabajo, por ser violatoria del preámbulo y de los artículos 1, 2, 5, 9, 25, 53 (inciso 4), 93, 228 y 230 de la Constitución. M. P.: Manuel José Cepeda Espinosa.
Consejo de Administración en el ordenamiento jurídico colombiano.

\section{Bloque de constitucionalidad según la Corte Constitucional}

"El bloque de constitucionalidad se refiere a aquellas normas y principios que sin aparecer formalmente en el articulado del texto constitucional, son utilizados como parámetros del control de constitucionalidad de las leyes, por cuanto han sido normativamente integrados a la Constitución, por diversas vías y por mandato propio" (Arango, 2004). Por ende, cualquier texto normativo que se encuentre dentro del llamado bloque de constitucionalidad ostenta jerarquía constitucional por estar situado a la altura de las normas del texto de la Carta y formar con él un conjunto normativo de igual rango (sentencia C-067 de 2003).

El concepto bloque de constitucionalidad empezó a ser utilizado por la Corte Constitucional solo hasta el año 1995, pero como contenido ya se venía aplicando desde anteriores años ${ }^{17}$ utilizando los valores y principios "en el texto constitucional para asegurar la permanencia y obligatoriedad del contenido material del mismo" (Arango, 2004). Hay que dejar claro que el concepto en sí fue importado de la jurisprudencia francesa, donde se le conoce como bloque de legalidad, término que es ampliamente distinto al utilizado en Colombia, ya que es de aplicación en el derecho administrativo (sentencia C-578 de 1995).

\footnotetext{
17 Al respecto se pueden citar las sentencias C-574 de 1992, C-225 de 1995, C-578 de 1995, C-191 de 1998 y C-401 de 2005, entre otras.
} 
Los artículos 93 y 94 de la Constitución Política de Colombia, fuente principal normativa de este, establecen lo siguiente:

Artículo 93. Los tratados y convenios internacionales ratificados por el Congreso, que reconocen los derechos humanos y que prohíben su limitación en los estados de excepción, prevalecen en el orden interno. Los derechos y deberes consagrados en esta Carta, se interpretarán de conformidad con los tratados internacionales sobre derechos humanos ratificados por Colombia.

Artículo 94. La enunciación de los derechos y garantías contenidos en la Constitución y en los convenios internacionales vigentes, no debe entenderse como negación de otros que, siendo inherentes a la persona humana, no figuren expresamente en ellos." [Subrayas fuera del texto].

De acuerdo con lo anterior, los tratados y convenios internacionales ratificados por Colombia, que reconocen los derechos humanos y que prohíben su limitación en los estados de excepción (también llamados derechos intangibles), prevalecen en el orden interno. Adicionalmente, la misma Carta establece que así algunos derechos de carácter fundamental no estén escritos dentro del texto no dejan por ello de serlo (también llamados derechos innominados). Como se evidencia, en ningún aparte de los citados artículos se encuentra que la Corte Constitucional tenga que pronunciarse para determinar qué tratados o qué convenios tienen rango constitucional.

Si se analizan de cerca los artículos anteriormente citados, se encuentra que los únicos re- quisitos que se deben cumplir para que los tratados y convenios tengan este alcance son: (i) que reconozcan derechos humanos y aquellos que prohíben su limitación en los estados de excepción, y (ii) que sean ratificados por el Congreso de Colombia. En principio, es posible afirmar que tanto el Estado como las personas privadas con carácter de empleadores tienen que respetar el contenido de derechos fundamentales de los convenios de la oit debidamente ratificados por Colombia, ya que ostentan jerarquía constitucional. Sin embargo, a pesar de lo anterior, la Corte Constitucional ha dicho lo contrario.

La Corte Constitucional ha establecido, como se dijo anteriormente, el alcance del bloque de constitucionalidad en una jurisprudencia abundante al respecto. Incluso hace diferencias entre el bloque de constitucionalidad 'en sentido lato' y 'en sentido estricto' (sentencia C-401 de 2005), estableciendo que algunos convenios de la olt hacen parte del primero y otros del segundo. Según la Corte, "la inclusión de los convenios internacionales del trabajo dentro del Bloque de Constitucionalidad debe hacerse de manera diferenciada y fundamentada. Si bien todos los convenios internacionales del trabajo ratificados por Colombia forman parte de la legislación interna, varios integran también el Bloque de Constitucionalidad, en sentido lato o en sentido estricto" (sentencia C-401 de 2005). Rodrigo Uprimny desarrolla de manera tangencial este tema, en su artículo de diciembre 12 de 2005, titulado Bloque de constitucionalidad, derechos humanos y nuevo procedimiento penal. 
Según la sentencia C-401 de 2005 de la Corte,

el espectro de temas tratados en los convenios internacionales del trabajo es muy amplio y diverso. El ámbito que tratan se extiende desde el relacionado con los derechos humanos fundamentales en el trabajo hasta el referido a puntos como la administración y las estadísticas del trabajo, pasando por el de la protección contra riesgos específicos como la cerusa en la pintura, el benceno, el asbesto, la maquinaria y el peso máximo por cargar. [Lo cual] hace necesario que para establecer cuáles convenios ratificados por Colombia integran el bloque de constitucionalidad es necesario que la Corte proceda a decidirlo de manera específica, caso por caso, tal como lo ha venido haciendo en las sentencias anteriormente citadas.

La anterior interpretación es totalmente desafortunada, ya que en sus anteriores sentencias, a pesar de haber nombrado la inclusión en el bloque lato y estricto de los convenios de la olт, no había mencionado que debiera hacerse "caso por caso", dando un viraje completo en el alcance de dichos convenios al condenar a aquellos ratificados por Colombia, que también desarrollan derechos fundamentales, a que hagan parte del bloque de constitucionalidad en estricto sentido, solamente cuando la Corte así lo determine y los analice en su jurisprudencia.

Dentro de los convenios estudiados por la Corte, y que según esta hacen parte del bloque de constitucionalidad 'en sentido estricto', se encuentran solamente el Convenio 169 sobre pueblos indígenas y tribales, el Convenio 87 so- bre la libertad sindical y el Convenio 98 sobre la aplicación de los principios de derechos de sindicalización colectiva (sentencia C-401 de 2005). Sin embargo, como se estudió anteriormente, existen otros convenios que incluso son de carácter fundamental en la oıt, pero no encuadran dentro de esta interpretación, solamente porque la Corte no los ha revisado específicamente. Estos convenios, también ratificados por Colombia, son los correspondientes a: la eliminación de todas las formas de trabajo forzoso $u$ obligatorio (C029), la igualdad de remuneración (C100), la abolición del trabajo forzoso (C105), la discriminación en materia de empleo y ocupación (C111), la edad mínima de admisión en el empleo (C138) y las peores formas del trabajo infantil (C182). Estos convenios, lastimosamente, fueron condenados por la Corte a no ser parte del bloque de constitucionalidad 'en sentido estricto', haciendo de estos preceptos internacionales del trabajo simples normas del mismo nivel de la ley, es decir, sin jerarquía constitucional. La pregunta que surge es: ¿acaso estos convenios no desarrollan derechos fundamentales distintos a los de asociación sindical y negociación colectiva?

Esta interpretación es entendible, en principio, ya que efectivamente, como dice la Corte, el espectro de los convenios de la oІт es muy amplio, dado que desarrollan desde derechos humanos fundamentales en el trabajo hasta temas de la administración y las estadísticas laborales, pasando por la protección contra riesgos específicos como la cerusa en la pintura, el benceno, el asbesto, la maquinaria, etc. Sin embargo, la interpretación de que la jerarquía constitucio- 
nal del convenio solamente se adquiere cuando este sea analizado por la Corte y esta así lo determine, implica una ampliación de la competencia de este tribunal muy poco ajustada a lo establecido por la Carta, puesto que como ya se demostró, los artículos 93 y 94 de la Constitución no establecen dicha valoración previa y, por tanto, es posible tildarla de inconstitucional. Lastimosamente, esta desafortunada interpretación ha permeado también la jurisprudencia que desarrolla el alcance de las decisiones de los órganos de control de la ort en el ordenamiento jurídico colombiano.

La hipótesis que se maneja a continuación es que solamente las decisiones con fundamento en los convenios 87 y 98 sobre libertad sindical son de referente preferencial constitucional en Colombia, al punto de poder ejecutarlas por medio de la acción de tutela (sentencia T-171 de 2011). Según la Corte Constitucional, el único órgano que tiene estas cualidades es el Comité de Libertad Sindical.

\section{Jurisprudencia constitucional sobre las decisiones del Comité de Libertad Sindical}

Como se dijo anteriormente, la jurisprudencia de la Corte Constitucional sobre el alcance de las decisiones del Comité de Libertad Sindical de la oाт ha sido amplia. En esta sección se estudiarán las siguientes sentencias: (i) la sentencia T-568 de 1999, (ii) la sentencia T-603 de 2003, (iii) la sentencia T-979 de 2004 y (iv) la sentencia T-171 de 2011. Vale la pena resaltar que no se trata de un análisis profundo sino de lo pertinente al tema desarrollado en la parte motiva de estas.
La sentencia T-568 de $1999^{18}$ es un hito en la jurisprudencia constitucional colombiana, por cuanto por primera vez se analiza el alcance "obligatorio" de las decisiones del Consejo de Administración con respecto al Estado colombiano. En este caso, la Corte Constitucional encuentra que las decisiones del Comité de Libertad Sindical de la оाт, adoptadas por el Consejo de Administración, no pueden ser ignoradas por el Estado colombiano, ni pueden ser interpretadas como las recomendaciones, las cuales son una figura distinta y no son de obligatorio cumplimiento.

Según la Corte,

el Comité de Libertad Sindical es un órgano de control de la oIT; confronta las situaciones de hecho que se le presentan o las normas internas de los Estados, con las normas internacionales aplicables según los Tratados ratificados por los Estados involucrados (en este caso, la Constitución de la ort y los Convenios sobre libertad sindical); luego, formula recomendaciones y las somete al Consejo de Administración, ya que este es el órgano que puede emitir recomendaciones de carácter vinculante según las normas que rigen la Organización. En este caso, el Consejo recibió el informe del Comité y

18 En esta sentencia de tutela, el sindicato de las Empresas Varias de Medellín E. P. S. (EEVVM) solicitó a través de la tutela, la protección de sus derechos constitucionales al trabajo, a la libertad sindical (asociación, organización y huelga) y al debido proceso, supuestamente vulnerados por las actuaciones y omisiones del Ministerio de Trabajo y Seguridad Social, el Ministerio de Relaciones Exteriores, el municipio de Medellín y las Empresas Varias de Medellín. Esta tutela tiene como fundamento, el hecho que el Sindicato, debido a su impotencia para obligar al Estado a respetar los derechos humanos laborales de los empleados despedidos luego de la declaración de ilegalidad de una huelga, y ante la falta de voluntad política del gobierno colombiano para cumplir sus obligaciones en cuanto hace a la adopción de una recomendación adoptada por el Comité de Libertad Sindical, y luego adoptada por el Consejo de Administración, acude a la tutela. 
sus recomendaciones y encontró que el asunto no requería mayor investigación, ni modificó los textos que se le presentaron; antes bien, los asumió, los incorporó a las actas de la reunión, y los publicó como parte de su informe oficial de esa sesión a la comunidad de Estados miembros; por tanto, esta recomendación constituye una orden expresa vinculante para el gobierno colombiano. Colombia está obligada, en virtud de su calidad de Estado Parte del Tratado Constitutivo de la oIt, a acatar las recomendaciones del Consejo de Administración (sentencia T-568 de 1999). [Subrayas fuera del texto].

En este orden de ideas, la Corte empieza aquí a desarrollar una jurisprudencia especial sobre el tema, abriendo la posibilidad (en principio) de que cualquier decisión adoptada por el Consejo de Administración sea de carácter obligatorio y sea posible ejecutarla por medio de la acción de tutela (acorde el artículo 86 de la cN), de modo que el Estado colombiano cumpla con las obligaciones internacionales contraídas en el ámbito de la ort.

Posteriormente, en la sentencia T-603 de $2003^{19}$ la Corte malinterpreta lo dicho en la

19 En esta sentencia de tutela, varios trabajadores sindicalizados del INPEC (ASEINPEC) son despedidos por inconveniencia, luego de decretarse un estado de emergencia carcelario en el año 2000. De los despedidos, cerca de 85 eran miembros de las juntas directivas del Sindicato a nivel nacional y de la Seccional de Antioquia. Los servidores despedidos elevaron demanda ante la justicia ordinaria, sin embargo el Tribunal Superior de Medellín no les dio la razón, argumentando que los servidores del INPEC no tienen derecho a fuero sindical, puesto que ostentan autoridad civil y funciones de confianza y manejo. Por esta razón, el sindicato acude ante la OIT -Comité de Libertad Sindical-, el cual en su reunión de 2002 recomendó a Colombia reintegrar a los servidores despedidos. El gobierno colombiano no cumple con la decisión, y por ende se ejerce la acción de tutela. anterior y establece erróneamente que solo las decisiones del Comité de Libertad Sindical son de carácter obligatorio en el derecho interno colombiano. Su pronunciamiento al respecto es el siguiente:

Esta Corporación tuvo oportunidad de analizar la naturaleza y alcances de las recomendaciones del Comité de Libertad Sindical de la oІт. En efecto, en la sentencia T-568 de 1999 la Corte Constitucional estableció el carácter vinculante de esas recomendaciones, atendiendo a las obligaciones contraídas por el Estado colombiano, al suscribir y ratificar el Tratado constitutivo de la oIт. Para tales efectos diferenció entre las recomendaciones emitidas por la olт y las de sus órganos de control. Así, dijo que a diferencia de los convenios, las recomendaciones pronunciadas por la oit no son normas creadoras de obligaciones internacionales, sino meras directrices, guías o lineamientos que deben seguir los Estados partes en busca de las condiciones dignas en el ámbito laboral de sus países; mientras que las recomendaciones de sus órganos de control en ocasiones son vinculantes. [Subrayas fuera del texto].

Si se lee con detenimiento, se encuentra que lastimosamente la decisión judicial le da un alcance interpretativo distinto a lo dicho por esta Corporación en la sentencia T-568 de 1999. A pesar de hablar de "órganos de control", la decisión se concentra en las recomendaciones del Comité de Libertad Sindical (tal vez por el asunto a resolver en la sentencia T-603 de 2003), delimitando el uso de la acción de tutela a la ejecución de las decisiones de este órgano en territorio colombiano. 
La Corte Constitucional también analiza el tema en la sentencia T-979 de 2004. ${ }^{20}$ Según esta, "las recomendaciones del Comité de Libertad Sindical de la ort no tienen carácter vinculante para los Estados Miembros de la Organización Internacional del Trabajo. Para que tales recomendaciones tengan efectos sobre los países Miembros se exige la adopción por el Consejo de Administración" [subrayas fuera del texto]. Para la Corte, las decisiones del Comité de Libertad Sindical no aprobadas por el Consejo de Administración son meras "recomendaciones provisionales" que finalmente no han adquirido ningún efecto vinculante para el Estado colombiano (sentencia T-979 de 2004). Por esta razón establece que

si las recomendaciones del Comité de Libertad Sindical en relación con los 155 trabajadores del sindicato accionante no pasan de ser recomendaciones provisionales, que aún no han adquirido fuerza vinculante para el Estado colombiano por cuanto no han sido adoptadas por el Consejo de Administración, mal podría el juez constitucional exigir a las entidades accionadas que las acaten o les den estricto cumplimiento. En ese sentido asiste la razón a los jueces de instancia al declarar improcedente la acción de tutela de la referencia, por cuanto no se han agotado todas las etapas del procedi- miento respectivo ante la Organización Internacional del Trabajo (sentencia T-979 de 2004).

De lo anterior se desprende que la Corte no solo reitera su jurisprudencia, sino que va más allá que en las anteriores decisiones judiciales, al dejar como precedente que la acción de tutela procede solamente para aquellos casos en que (i) la recomendación es emitida por el Comité de Libertad Sindical y (ii) la recomendación es adoptada por el Consejo de Administración.

Finalmente, la sentencia T-171 de $2011^{21}$ contiene la última decisión judicial de la alta Corte sobre el alcance y obligatoriedad de las decisiones del Consejo de Administración en el ordenamiento jurídico colombiano. En esta ocasión, haciendo alusión a la sentencia C-401 de 2005 -estudiada en el aparte relativo al bloque de constitucionalidad-, reitera que efectivamente los convenios 87 y 98 de la oाт hacen parte del bloque y que "dada la diversidad de temas tratados en los convenios internacionales sobre aspectos laborales, la Corte ha sostenido que su inclusión en esta figura debe hacerse de manera diferenciada y fundamentada, caso por caso, tal como lo ha venido haciendo" (sentencia T-171 de 2011).

21 En esta acción de tutela, trabajadores vinculados a Ecopetrol son despedidos por participar en una huelga denominada "Huelga por la defensa de Ecopetrol", llevada a cabo en el año 2004. Con fundamento en la declaratoria de ilegalidad de la huelga, se produjo el despido de 248 trabajadores por haber sido disciplinados. Al finalizar los procesos, más de la mitad de los trabajadores fueron destituidos e inhabilitados por 10 o 20 años para el ejercicio de cargos públicos, entre ellos los accionantes. El tema fue puesto a consideración de la OIT ante el Comité de Libertad Sindical, el cual realizó recomendaciones, y aprobado por el Consejo de Administración, frente al reintegro de los trabajadores. Los accionantes afirmaron que las decisiones de este órgano no fueron acogidas, por lo cual interponen acción de tutela. 
Asimismo, cita las sentencias T-568 de 1999 y la T-603 de 2003, jurisprudencia que según su concepto,

ha sido uniforme al considerar que las recomendaciones proferidas por el Comité de Libertad Sindical de la oit debidamente aprobadas por el Consejo de Administración, tienen una orden expresa de carácter vinculante para el Estado colombiano y por tanto es imperativo el acatamiento de lo allí ordenado. La sustracción de su cumplimiento implica la violación de derechos fundamentales alegados, además de desconocer el carácter vinculante de la jurisprudencia de la Corte Constitucional que fija los alcances de los derechos fundamentales (sentencia T-171 de 2011) [subrayas fuera del texto].

La Corte, a pesar de no tutelar los derechos fundamentales invocados por la existencia de otros mecanismos de defensa judicial y por la carencia actual del objeto, por configurarse un hecho superado, reitera la jurisprudencia desafortunada sobre el bloque de constitucionalidad 'en sentido estricto', como también le da un alcance imperativo y obligatorio a las recomendaciones del Comité de Libertad Sindical debidamente adoptadas por el Consejo de Administración, lo cual implica la violación de derechos fundamentales y el desconocimiento de su propia jurisprudencia.

En este sentido, la Corte limita el uso de la acción de tutela a las recomendaciones del Comité de Libertad Sindical, como también limitó en su momento el carácter jerárquico de los convenios de la ort y su vinculación al concepto de bloque de constitucionalidad 'en sentido estricto'.
En este orden de ideas, termina dándole mayor importancia y prevalencia constitucional a los convenios 87 y 98 de la ort y a las decisiones del Comité de Libertad Sindical debidamente acogidas por el Consejo de Administración.

Lo anterior deja como conclusión que la Corte Constitucional, partiendo de una mala interpretación de los artículos 93 y 94 de la Constitución Política, (i) finaliza excluyendo otros convenios, que a pesar de encontrarse en el bloque de constitucionalidad 'en sentido lato' no tienen fuerza constitucional, aunque desarrollan igualmente derechos fundamentales en el lugar de trabajo, como por ejemplo, los número 29, 105, 138, 182, 100 y 111; y (ii) termina dándole mayor alcance e importancia constitucional a las decisiones del Comité de Libertad Sindical, exceptuando las de otros órganos también muy importantes como la Comisión de Aplicación de Normas de la Conferencia, la Comisión de Expertos en Aplicación de Convenios y Recomendaciones, los comités o comisiones ad hoc, la Comisión de Encuesta y la Comisión de Investigación y Conciliación en Materia de Libertad Sindical. Estos tienen alta relevancia por cuanto sus decisiones también determinan el cumplimiento de los Estados miembro en asuntos referentes a los convenios 87 y 98, así como del $29,105,138,182,100,111$ y otros que igualmente desarrollan derechos fundamentales en el lugar de trabajo, pero que bajo la lupa de la Corte no tienen fuerza constitucional por no encontrarse en el bloque de constitucionalidad 'en sentido estricto'. 
La Corte Constitucional debería cambiar su jurisprudencia y darle la importancia y visibilidad que merecen (i) los otros convenios de la oit que desarrollan derechos fundamentales (distintos al 87,98 y 169) y (ii) las decisiones de los otros órganos de la oІт.

Como se demuestra, la Corte Constitucional ha mantenido una jurisprudencia bajo una indebida interpretación de los artículos 93 y 94 de la Constitución Política, teniendo como consecuencia la exclusión del bloque de constitucionalidad 'en sentido estricto' de otros convenios distintos a los 87, 98 y 169 de la olт, como también restándole importancia y obligatoriedad constitucional a las decisiones de otros órganos de la oıт diferentes al Comité de Libertad Sindical, cuyas decisiones se basan en los convenios citados.

\section{CONCLUSIONES}

En el presente trabajo se hizo (i) un breve recuento sobre los inicios y la estructura de la Organización Internacional del Trabajo, (ii) un estudio general de las normas internacionales del trabajo, su procedimiento, su obligatoriedad y sus mecanismos de cumplimiento y (iii) un análisis sucinto de las decisiones del Consejo de Administración de la olt, por medio de sus comités ad hoc y su Comité de Libertad Sindical a la luz de la jurisprudencia constitucional colombiana.

El primer punto mostró la larga historia de la oIT y el desarrollo institucional-organizacional que ha tenido a través de sus órganos principales (la Conferencia Internacional del Trabajo, el Con- sejo de Administración y la Oficina Internacional del Trabajo) y especializados (Comisión de Aplicación de Normas de la Conferencia o los comités ad hoc), cuya función es el control y monitoreo del cumplimiento por parte de los Estados miembro de sus obligaciones internacionales respecto de la olt.

El segundo punto evidenció la diferencia entre las recomendaciones y los convenios, por su nivel de obligatoriedad, su procedimiento de adopción y sus mecanismos de cumplimiento, y se ocupó de la importancia de los llamados convenios fundamentales, por corresponder a temas considerados principios y derechos fundamentales en el trabajo, como son la libertad de asociación sindical y la libertad sindical, el reconocimiento del derecho de negociación colectiva, la eliminación de todas las formas de trabajo forzoso u obligatorio, la abolición efectiva del trabajo infantil y la eliminación de la discriminación en materia de empleo y ocupación y que tienen la misma importancia material que aquellos relacionados con el derecho de asociación, libertad y negociación colectiva.

En el tercer punto se analizó el alcance que la jurisprudencia constitucional colombiana le ha dado a las decisiones de los órganos de la ort dentro del ordenamiento jurídico del país, encontrando que la Corte Constitucional ha sido prolífica, pero desafortunada en dos aspectos:

(i) el bloque de constitucionalidad 'en sentido estricto' y 'en sentido lato', ya que por un error de interpretación de los artículos 93 y 94 de la Constitución terminó condenando los convenios 
de la olt ratificados por Colombia, que también desarrollan derechos fundamentales, a que su jerarquía constitucional dependa de cuando ella así lo determine, los analice en su jurisprudencia y los incluya en el bloque 'en sentido estricto', dejando al mismo nivel de la ley los convenios 29, 105, 138, 182, 100 y 111 relativos a la eliminación de todas las formas de trabajo forzoso u obligatorio, la abolición efectiva del trabajo infantil y la eliminación de la discriminación en materia de empleo y ocupación.

(ii) la obligatoriedad de las decisiones del Comité de Libertad Sindical, a las que como consecuencia de la interpretación y diferenciación errada del bloque de constitucionalidad acabó dándoles mayor alcance e importancia que a las de otros órganos igualmente valiosos como la Comisión de Aplicación de Normas de la Conferencia, la Comisión de Expertos en Aplicación de Convenios y Recomendaciones, los comités o comisiones ad hoc, la Comisiones de Encuesta y la Comisión de Investigación y Conciliación en Materia de Libertad Sindical, cuyos análisis y dictámenes amparan derechos fundamentales que pueden ser vulnerados en el ámbito laboral.

Los problemas de interpretación por parte de la Corte Constitucional de los artículos 93 y 94 de la Constitución Política tienen que ver con el hecho de otorgarse competencias que estos no le han dado. Para que la tesis de la Corte fuese totalmente congruente con el contenido del texto normativo constitucional, los art, tanto en sentencias de tucional determinarente con el contenido del texto normativo constitucional, los arttermina ds Estados ículos antes mencio- nados deberían incluir como supuesto fáctico que la Corte Constitucional determinará tanto en sentencias tipo $\mathrm{C}$ como tipo $\mathrm{T}$, si el contenido de los tratados del trabajo desarrollan derechos fundamentales $y$, por ende, tienen un alcance constitucional, es decir, de derechos innominados, pero esto no es así.

Algunos dirán que el numeral 10 del artículo 241 de la Constitución Política, al instituir que a la Corte Constitucional se le confía "decidir definitivamente sobre la exequibilidad de los tratados internacionales y de las leyes que los aprueben", le reconoció la posibilidad de establecer el alcance constitucional de cualquier tratado, incluidos aquellos del trabajo. Sin embargo, en el presente caso no está determinando la exequibilidad de los tratados del trabajo sino su rango constitucional, razón por la cual este contraargumento no prosperaría.

Adicionalmente, esta interpretación por parte de la Corte tiene varias consecuencias hacia el futuro. La primera es que si los distintos casos de acciones de tutela que tengan como fuente tratados o convenios del trabajo no llegan a ser analizados por la Corte Constitucional (que pueden ser la mayoría), los jueces constitucionales inferiores, siguiendo el precedente constitucional, podrían determinar que los derechos reclamados por los accionantes no son fundamentales, con lo cual se dejarían en desamparo todos aquellos derechos no desarrollados por la Carta pero que se encuentran en Convenios. Como consecuencia, sería ilógico invocar tratados del trabajo en las acciones de tutela, puesto que si llegaran a ser admitidas lo más seguro es que el 
proceso culminaría con una decisión desfavorable para el accionante.

La segunda es que los convenios no elevados por la Corte a rango constitucional, si bien tendrían que ser acatados tanto por el Estado como por los ciudadanos con el carácter que les reconoce el bloque de constitucionalidad en sentido lato, habría que recordar que la mayoría de estos contienen normas de tipo "principio", a diferencia de las leyes que contienen normas de tipo "regla" (Alexy, 1988), ${ }^{22}$ con lo cual habría un problema de adjudicación en las manos de los jueces, en tanto no se podría aplicar la figura de la subsunción, dejando entonces el contenido de estos tratados inoperantes o difícilmente aplicables también ante la justicia ordinaria. Las normas-principio no manejan supuestos fácticos específicos, con consecuencias definidas, como cuando el operador jurídico se encuentra frente a una norma-regla.

La tercera consecuencia negativa es que hace ineficaz judicialmente el contenido normativo de los convenios, cuestionando en parte su alcance vinculante para el Estado colombiano. Bajo esta interpretación, internamente, los convenios tienen un alcance vinculante restringido, en tan-

22 Para Robert Alexy (1988), "el punto decisivo para la distinción entre reglas y principios es que los principios son normas que ordenan que se realice algo en la mayor medida posible, en relación con las posibilidades jurídicas y fácticas. Los principios son, por consiguiente, mandatos de optimización que se caracterizan porque pueden ser cumplidos en diversos grados y porque la medida ordenada de su cumplimiento no solo depende de las posibilidades fácticas, sino también de las posibilidades jurídicas (...). En cambio, las reglas son normas que exigen un cumplimiento pleno y, en esa medida, pueden ser solo o cumplidas o incumplidas. Si una regla es válida, entonces es obligatorio hacer precisamente lo que ordena, ni más ni menos. Las reglas contienen por ello determinaciones en el campo de lo posible fáctica y jurídicamente". to se podrían invocar ante la justicia ordinaria pero no ante el juez constitucional. Es decir, nos encontramos en un escenario parecido al de las “normas de papel” (García, 2009).

En conclusión, la Corte Constitucional debe (i) cambiar su jurisprudencia para darle la importancia y visibilidad que merecen los otros convenios de la oाт que desarrollan derechos fundamentales distintos a los amparados en los convenios 87, 98 y 169, así como a las decisiones de los otros órganos de la ort que tienen como base normativa estos tratados, o (ii) modificar la diferenciación y noción del bloque de constitucionalidad 'en sentido estricto' y 'en sentido lato' o simplemente eliminarla totalmente para poder incluir también a los otros convenios y darles rango constitucional en concordancia con lo establecido en la Constitución en los artículos 93 y 94 . De ser así, a) se podrían amparar, defender y hacer justiciables de manera efectiva e integral todos los derechos fundamentales relevantes en el lugar de trabajo, así no estén textualmente en la Constitución Política de Colombia; b) se harían operantes y relevantes los convenios en el momento de su aplicación judicial, dándoles el verdadero carácter vinculante que tienen estos en el ordenamiento jurídico colombiano.

\section{Bibliografía}

Alexy, R. (1988). Sistema jurídico, principios y razón práctica. Doxa, (5).

Arango, M. (2004). El Bloque de Constitucionalidad en la jurisprudencia de la Corte Constitu- 
cional. Precedente. Revista Jurídica, 79-102.

Aust, A. (2005). Handbook of International Law. Cambridge: Cambridge University Press.

Bronstein, A. (2009). International and Comparative Labour Law: Current Challenges. Geneva: International Labour Organization.

Corte Constitucional. Sentencia C-574 del 28 de octubre de 1992. M. P.: Ciro Angarita Barón.

Corte Constitucional. Sentencia C-225 del 18 de mayo de 1995. M. P.: Alejandro Martínez Caballero.

Corte Constitucional. Sentencia C-578 del 4 de diciembre de 1995. M. P.: Eduardo Cifuentes Muñoz.

Corte Constitucional. Sentencia C-191 del 6 de mayo de 1998. M. P.: Eduardo Cifuentes Muñoz.

Corte Constitucional. Sentencia T-568 del 10 de agosto de 1999. M. P.: Carlos Gaviria Díaz.

Corte Constitucional. Sentencia T-1022 del 16 de diciembre de 1999. M. P.: Alejandro Martínez Caballero.

Corte Constitucional. Sentencia C-067 del 4 de febrero de 2003. M. P.: Marco Gerardo Monroy Cabra.

Corte Constitucional. Sentencia T-603 del 23 de julio de 2003. M. P.: Jaime Araujo Rentería.
Corte Constitucional. Sentencia T-979 del 8 de octubre de 2004. M. P.: Jaime Córdoba Triviño.

Corte Constitucional. Sentencia C-401 del 14 de abril de 2005. M. P.: Manuel José Cepeda Espinosa.

Corte Constitucional. Sentencia T-171 del 14 de marzo de 2011. M. P.: Jorge Iván Palacio Palacio.

Corte Suprema de Justicia. Sala de Casación Laboral. Rad. 11731 del 8 de octubre de 1999. M. P.: Carlos Isaac Nader.

Corte Suprema de Justicia. Sala de Casación Laboral. Rad. 1701 del 28 de marzo de 2003. M. P.: Isaura Vargas Díaz.

Corte Suprema de Justicia. Sala de Casación Laboral. Rad. 20063 del 6 de agosto de 2003. M. P.: Fernando Vásquez Botero.

Corte Suprema de Justicia. Sala de Casación Laboral. Rad. 32703 del 31 de mayo de 2011. M. P.: Jorge Mauricio Burgos.

Crowe, C. (2010). Consensus Forecast and Inefficient Information Aggregation. IMF Working Paper. WP/10/178.

García, M. (2009). Normas de papel: la cultura del incumplimiento de reglas. Bogotá: Siglo del Hombre Editores. 
International Institute of Labour Studies. (2010). World of Work Report 2010 - from one crisis to the next? Geneva: ıL.

Klabbers, J. (2002). An introduction to International Institutional Law. New York: Cambridge University Press.

McKillen, E. (2010). Beyond Gompers: The American Federation of Labor, the creation of the ILO and US labor dissent. En J. van Daele, M. Rodríguez, G. van Goethem y M. van der Linden (Edits.), ILO Histories: Essays on the International Labor Organization and its impact on the world during the twentieth century (pág. 539). Berna: Peter Lang, AG, International Academic Publisher.

Ministerio de Trabajo y Seguridad Social. (2000). Convenios internacionales del trabajo ratificados por Colombia. Bogotá: Ediciones Cambios para Construir la Paz.

Monroy, M. (1977). Introducción al derecho internacional laboral. Bogotá: Ediciones Rosaristas.

Oficina Internacional del Trabajo. (2006). Manual sobre procedimientos en materia de convenios y recomendaciones internacionales del trabajo. Ginebra: Departamento de Normas Internacionales del Trabajo, oІт.

Organización Internacional del Trabajo. (2005). Las reglas del juego: una breve introducción a las normas internacionales del trabajo. Ginebra: Oficina Internacional del Trabajo, отт.
Organización Internacional del Trabajo, Centro Internacional de Formación. (2009). Derecho internacional del trabajo y derecho interno. Manual para jueces, juristas y docentes en derecho. Turin: oIT.

Ostau de Lafont, F. y Niño, L. (Enero-Junio de 2011). El carácter vinculante de las recomendaciones del comité de libertad sindical en el contexto jurídico colombiano. Revista Verba luris, 41-61.

Rodgers, G., Lee, E., Swepston, L. y van Dale, J. (2009). The International Labor Organization and the quest for justice 1919-2009. Ginebra: International Labor Office, ıL.

Rodríguez, A., Belkis, A. y Yanuzzi, J. (2010). La Organización Internacional del Trabajo (oiт). Existencia, importancia y trascendencia. Revista Cifra, (5), 39.

Rodríguez, M. (2010). The ILo's impact on the world. En J. van Daele, M. Rodríguez, G. van Goethem y M. van der Linden (Edits.), ıo Histories: Essays on the International Labor Organization and its impact on the world during the twentieth century. Berna: Peter Lang, AG, International Academic Publisher.

Segura, D. (20 de julio de 2012). Poder vinculante de las recomendaciones de la oit según las altas Cortes. Boletín Discurso Laboral.

Triana, F. (1978). Derechos humanos y garantías sindicales. Convenios 87 y 98 de la olt. Colombia: leyes 26 y 27 de 1976. Bogotá: Editorial Gráficas Pazgo. 
Tsogas, G. (2001). Labor Regulation in a Global Economy. New York: M. E. Sharpe.

Uprimny, R.(2005). Bloquedeconstitucionalidad, derechos humanos y nuevo procedimiento penal. Recuperado de http://www.dejusticia. org/index.php?modo=interna\&tema=estado_ de_derecho\&publicacion $=73$

Ureña, R. (2008). Derecho de las organizaciones internacionales. Bogotá: Ediciones Uniandes, Editorial Temis.
Van Daele, J. (2010). Writing ILo histories. A state of the art. En J. van Daele, M. Rodríguez, G. van Goethem y M. van der Linden (Edits.), ILO Histories: Essays on the International Labor Organization and its impact on the world during the twentieth century. Berna: Peter Lang, AG, International Academic Publisher.

Von Potobsky, G. y Bartolomei, H. (1990). La Organización Internacional del Trabajo. Buenos Aires: Ediciones Astrea. 